\title{
Simulation of Wound Rotor Synchronous Machine under Voltage Sags
}

\author{
D. Aguilar ${ }^{1}$, G. Vazquez, Student Member, IEEE, A. Rolan, Student Member, IEEE, \\ J. Rocabert, Student Member, IEEE, F. Córcoles, Member, IEEE, and P. Rodríguez, Member, IEEE. \\ Electrical Department of Engineering \\ Technical University of Catalonia \\ Colom 1- 08222-Terrassa, Spain \\ ${ }^{1}$ Contact Author: aguilar.seer@gmail.com
}

\begin{abstract}
This paper presents a study of the Wound Rotor Synchronous Machine (SM) stability under voltage sags (dips). Machine behavior has been analyzed by considering different magnitudes (or depths) and duration of the sag. Voltage sags cause speed variations on SM (with possible lost of synchronism), current and torque peaks and hence may cause tripping and equipment damage, which leads to financial losses. Three machines of different nominal power have been modeled and simulated with MATLAB in order to study its behavior under voltage sags. These SM's have been analyzed operating as generator, as motor, and in both cases, working under-excited and overexcited.
\end{abstract}

\section{INTRODUCTION}

Nowadays, electrical power systems are constituted by many generation sources. Nevertheless, the vast majority of the electrical power generation systems consist of synchronous generators coupled to the electrical grid through a transformer. This is due to its capability of generating electricity in large scale power plants [1]. Large (in the MVA range) and small (in the $\mathrm{kVA}$ range) synchronous generators are part of electrical system and hence its behaviour is a very important issue.

Moreover, during the last years, the power quality has gained a great importance in both industry and research, due to technical and situational factors, such as the equipment sensibility (which are also the cause of perturbations), distributed generation, new grid code requirements for specific power supply, by mentioned just a few.

The grid may present many types of disturbances, being the voltage sags the most common ones. The principal causes of voltage sags are faults, large transformer energizing and the starting of large motors. The interest in studying this kind of disturbances is mainly due to the problems that they cause in electrical equipments [2]. Voltage sags may cause large torque peaks on SM, and it can damage the shaft or the equipment connected to the shaft [3]. In addition, voltage sags may cause tripping, which leads to financial losses.

On the other hand, the simulation of the SM's behaviour under voltage sags permits defining different criteria for protecting and preventing potential damages in such machines, as well as the effects on the power supply interruptions [4]. Hence, a valid model for SM is essential in order to obtain a reliable analysis of stability and dynamical performance.

In [5] it has been presented the transient behaviour of SM under sags according to their duration, depth, and initial pointon-wave. The aim of this paper is to simulate the wound rotor
SM and study its stability under a wide variety of symmetrical and unsymmetrical voltage sags, considering its performance as generator, as motor and in both cases, operating underexcited and overexcited. Section II presents the voltage sags classification and characterization. Section III shows the wound rotor SM model. Finally, based on the simulations using MATLAB, voltage sags effects on SM stability are presented in section IV.

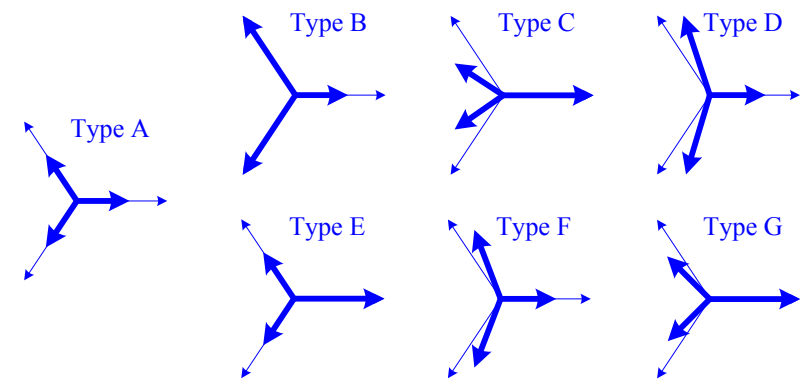

Fig. 1. Voltage sag types: Symmetrical (type A) and unsymmetrical (type B G). All sags have a depth of 50\%. [2]

TABLE I

Positive, NegAtive AND ZERo SEQUENCE EXPRESSIONS FOR VOLTAGE SAGS [2]

\begin{tabular}{lccc} 
Type & Positive & Negative & Zero \\
$\mathrm{A}$ & $V_{A}^{+}=h \cdot \underline{V}$ & $V_{A}^{-}=0$ & $V_{A}^{0}=0$ \\
$\mathrm{~B}$ & $V_{B}^{+}=\frac{2+h}{3} \cdot \underline{V}$ & $V_{B}^{-}=-\frac{1-h}{3} \cdot \underline{V}$ & $V_{B}^{0}=-\frac{1-h}{3} \cdot \underline{V}$ \\
$\mathrm{C}$ & $V_{C}^{+}=\frac{1+h}{2} \cdot \underline{V}$ & $V_{C}^{-}=\frac{1-h}{2} \cdot \underline{V}$ & $V_{C}^{0}=0$ \\
$\mathrm{D}$ & $V_{D}^{+}=\frac{1+h}{2} \cdot \underline{V}$ & $V_{D}^{-}=-\frac{1-h}{2} \cdot \underline{V}$ & $V_{D}^{0}=0$ \\
$\mathrm{E}$ & $V_{E}^{+}=\frac{1+2 \cdot h}{3} \underline{V}$ & $V_{E}^{-}=\frac{1-h}{3} \cdot \underline{V}$ & $V_{E}^{0}=\frac{1-h}{3} \cdot \underline{V}$ \\
$\mathrm{~F}$ & $V_{F}^{+}=\frac{1+2 \cdot h}{3} \underline{V}$ & $V_{F}^{-}=-\frac{1-h}{3} \cdot \underline{V}$ & $V_{F}^{0}=0$ \\
$\mathrm{G}$ & $V_{G}^{+}=\frac{1+2 \cdot h}{3} \underline{V}$ & $V_{G}^{-}=\frac{1-h}{3} \cdot \underline{V}$ & $V_{G}^{0}=0$ \\
\hline
\end{tabular}




\section{Voltage SAgS (DiPS)}

A voltage sag is a short-duration (from half cycle to 1 minute) drop between $10 \%$ and $90 \%$ in the magnitude of the $r m s$ voltage. When the voltage sag is caused by short-circuit, the tripping time must limit the fault between 3 and 30 cycles. Nevertheless, voltage sags duration due to large motors can be of some seconds [2] [6].

Voltage sags can be either symmetrical or unsymmetrical, depending on the causes. If the individual phase voltages are equal and the phase relationship is $120^{\circ}$, the sag is symmetrical. Otherwise, the sag is unsymmetrical.

According to [2], voltage sags can be grouped into seven types denoted as A, B, C, D, E, F and G (of which C and D cover the majority of sag). This classification is based on the fault type and connection: if the fault is three-phase the sag type is A (both star and delta connection). When the fault is single-phase the sag types are B (star connection) and C (delta connection). The sag types are also $\mathrm{C}$ (star connection) and $\mathrm{D}$ (delta connection) if the fault is phase-to-phase. Finally, in two-phase-to-ground faults the sag types are E (star connection) and F (delta connection). Sag types E and G only differ in the zero-sequence voltage.

Table I and II show their expressions (where $h$ is the sag depth), both in positive-negative-zero variables and in perphase variables, respectively. The first table make evident the difference between sag type $\mathrm{E}$ and $\mathrm{G}$ mentioned above and also that symmetrical ones are the most severe voltage sag types. Fig. 1 shows their phasor diagrams.

In order to simulate the behaviour of SM, in this paper it has been considered that the sag shape is rectangular, no phase jump occurs and the sag type does not change when the fault is cleared. The depth (or magnitude) and duration are the main characteristics of the voltage sags, but do not completely characterize the sag. Hence, the voltage sags will be defined by their depth $h(0.1 \leq h \leq 0.9)$, their duration $\Delta t$, and their initial point-on-wave $\psi_{i}$ [7].

\section{WOUnd Rotor SYNCHRONOUS MACHINE MODEL}

In this paper a SM eight-order model is used in order to evaluate its behaviour under voltage sags (damper winding exist in both $d$ and $q$ axis). The dynamic equation in the $d q$ reference frame of SM is given by [8]. The dynamic expression in form of state equations can be written as:

$$
\begin{aligned}
& \frac{d}{d t}\left(\mathbf{i}_{p}\right)=\mathbf{M}_{p}^{-1}\left\{\mathbf{v}_{p}-\mathbf{R} i_{p}-\omega \mathbf{M}_{p} \mathbf{i}_{p}\right\} \\
& \frac{d \omega_{m}}{d t}=\frac{1}{J}\left\{\Gamma(t)-\Gamma_{r e s}(t)\right\} \\
& \frac{d \theta}{d t}=\omega_{m}
\end{aligned}
$$

Where $\mathbf{i}_{p}$ is the vector which contains the Park's stator and rotor currents, $\mathbf{v}_{p}$ is the vector that includes the transformed stator and rotor voltages, $\mathbf{R}$ is the winding resistance matrix and $\mathbf{M}_{p}$ is the transformed inductance matrix. The mechanical equations are given in (2) and (3).
TABLE II

SAG TYPES IN EQUATION Form (OBTAINED FROM [2])

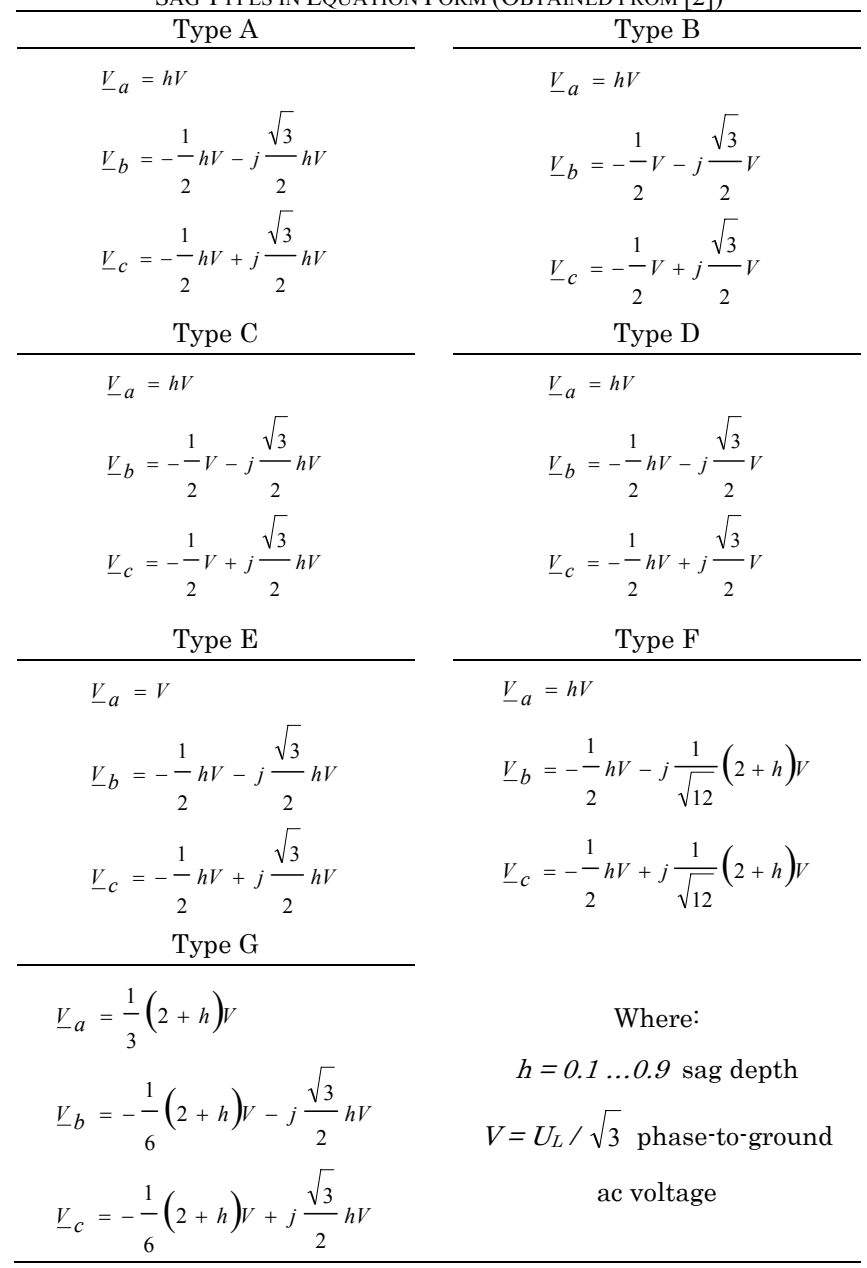

Saturation is not considered. An equivalent circuit is shown in Fig. 2. The instantaneous electromagnetic torque $\Gamma(t)$ and the load angle $\delta(t)$ (measured in steady-state from phasor $\underline{E}_{s}$ to phasor $\left.\underline{U}_{s}\right)$ are expressed as:

$$
\begin{gathered}
\Gamma(t)=i_{s q}\left(M_{d} i_{F}+M_{d} i_{D}\right)-i_{s d}\left(M_{q} i_{Q}\right)+\ldots \\
\ldots+\left(L_{d}-L_{q}\right) i_{s d} i_{s q} \\
\delta(t)=\left(\omega_{s} t+\varphi_{s}\right)-(\theta(t)+\pi / 2)
\end{gathered}
$$

When the SM has round-rotor $\left(L_{d}=L_{q}\right)$, the instantaneous electromagnetic torque is reduced to:

$$
\Gamma(t)=i_{s q}\left(M_{d} i_{F}+M_{d} i_{D}\right)-i_{s d}\left(M_{d} i_{Q}\right)
$$

Moreover, the matrix of magnetic flux $\varphi_{p}$ is expressed as:

$$
\boldsymbol{\varphi}_{p}=\mathbf{M}_{p} \mathbf{i}_{p}
$$


Three SM have been simulated: a high-speed steam turbine generator (835MVA), a low-speed hydro turbine generator (325MVA), both obtained from [8], and a small generator. Rated parameters of these machines are included in Appendix.

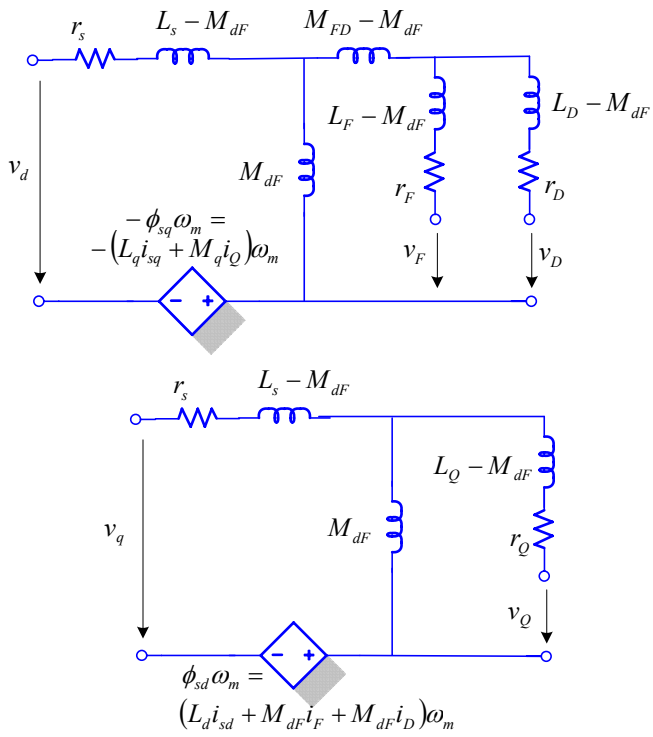

Fig. 2. Synchronous machine equivalent circuits.

\section{Voltage Sags EfFects on Wound Rotor SYNCHRONOUS MACHINE}

In [5] it has been demonstrated the effects on SM using recursive simulation for each sag characteristic: depth, duration and initial point-on-wave. The depth influence on the torque peaks is linear and the duration influence on torque peaks is periodical, for all sag types. In addition, different initial pointon-wave can produce peaks with different amplitude for unsymmetrical sags.

The most relevant voltage sag effects on the SM behaviour are speed variations, with possible loss of synchronism, current and torque peaks, as well as tripping protection. The machine behaviour is different when symmetrical and unsymmetrical sags are produced in the grid.

Fig. 3 shows the transient effects caused by symmetrical sag on the 5kVA SM, whose duration and depth are 100 milliseconds and 20 per cent of rms voltage, respectively. When symmetrical sag is applied on this machine, the most severe peaks occur at the beginning and at the end of the sag, because symmetrical sags do not have negative sequence voltage, thus the waveform is not oscillatory.

Fig. 4 shows the SM behaviour against an unsymmetrical voltage sag type $\mathrm{C}$ on the $5 \mathrm{kVA} \mathrm{SM}$ with the same characteristics. In this case, the instantaneous active and reactive power has a higher distortion, but their peak values are smaller when the sag starts as well as when the sag ends. It is due to the fact that the positive sequence voltage applied to the machine is higher for the unsymmetrical sag than for the symmetrical sag [7]. As can be deduced from Table I, the minimum positive sequence voltages available (when $h=0$ ) in
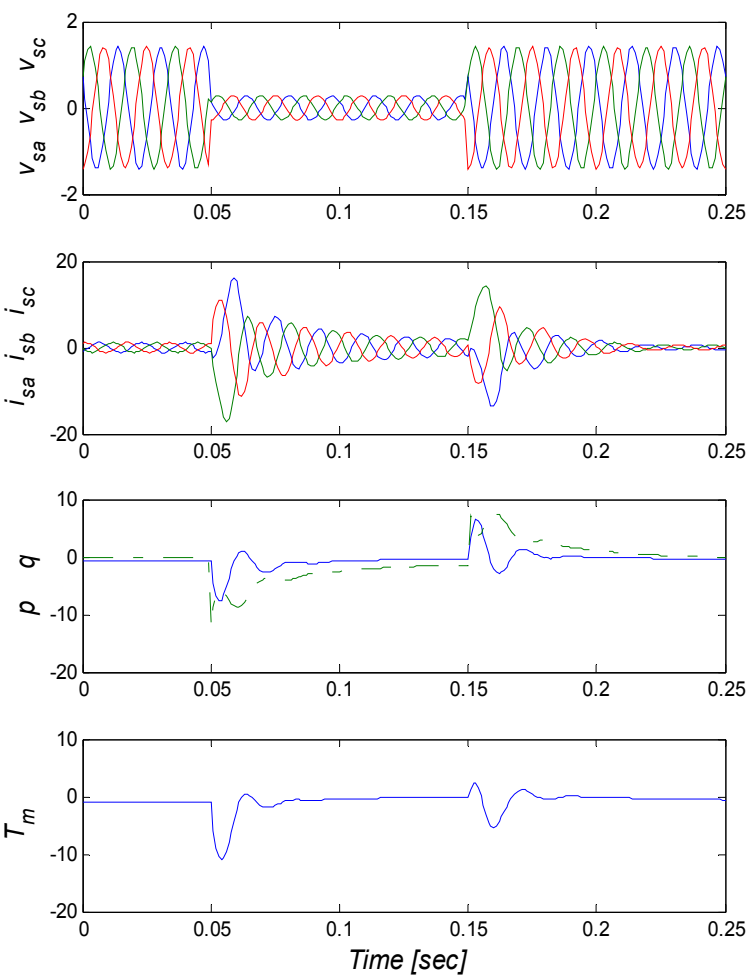

Fig. 3. 5kVA Synchronous Machine behaviour for a symmetrical voltage sag: type A, $h=0.2, \Delta t=100 \mathrm{~ms}, \psi_{i}=30^{\circ}$
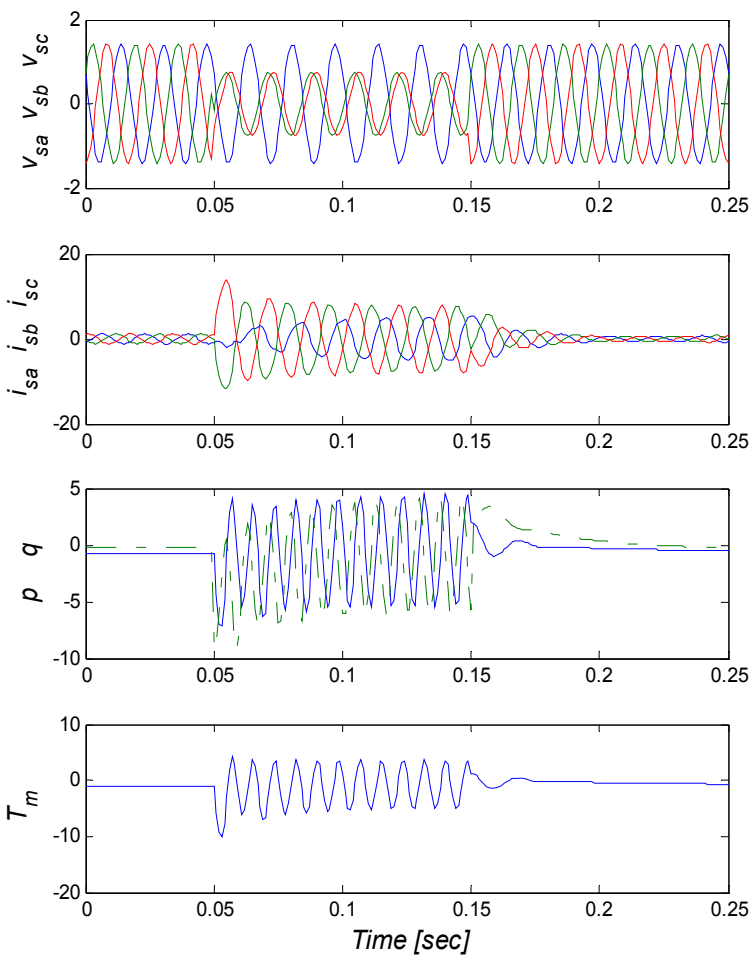

Fig. 4. 5kVA Synchronous Machine behaviour for a unsymmetrical voltage sag: type C, $h=0.2, \Delta t=100 \mathrm{~ms}, \psi_{i}=30^{\circ}$ 
the all unsymmetrical sags are $0.66 \mathrm{~V}$ (type B), $0.5 \mathrm{~V}$ (types $\mathrm{C}$ and D) and $0.33 \mathrm{~V}$ (types E, F and G). Moreover, due to fact that the machine losses are small and the machine speed is nearly constant, torque and active power have the same waveform. The reactive power (shown in dotted line in Fig. 4) has an oscillatory behaviour for all the unsymmetrical sags because of their negative sequence voltage.

According to the simulation that has been carried out on three machines, an increase in the sag duration leads to an increase in the current peaks when the sag ends. On the whole, the transient wave shape caused by voltage sag depends on different factors such as its depth, duration, initial point-onwave and machine parameters.

On the other hand, when voltage sags occurs on the SM operating as generator, for example due to a three-phase short circuit at some point common coupling (PCC) near to the machine, the rotor speed increases steadily. This fact occurs because the terminal voltage (which decreases due to sag) is proportional to the electrical torque, thus it also decreases; in consequence, the rotor speed increases in order to compensate the electrical torque reduction. Since a determined point of view, the rotor speed could increase unlimitedly and cause an over-speed on the machine, which could lead to collapse the system. At this point, of course, the generator should be disconnected by the protection system and returning to a new steady state.

Fig. 5 confirms the above mentioned. During the voltage sags, the SM accelerates if it is working as a generator (or reduces its speed if it is operating as a motor), so that it may become unstable due to loss of synchronism. In this case, rotor speed behaviour of both hydro and steam machine have been simulated when a symmetrical sag occurs at terminal voltage. Voltage sag, which depth is $20 \%$ of rms voltage, beginning at 50 milliseconds and it finish at 250 milliseconds.

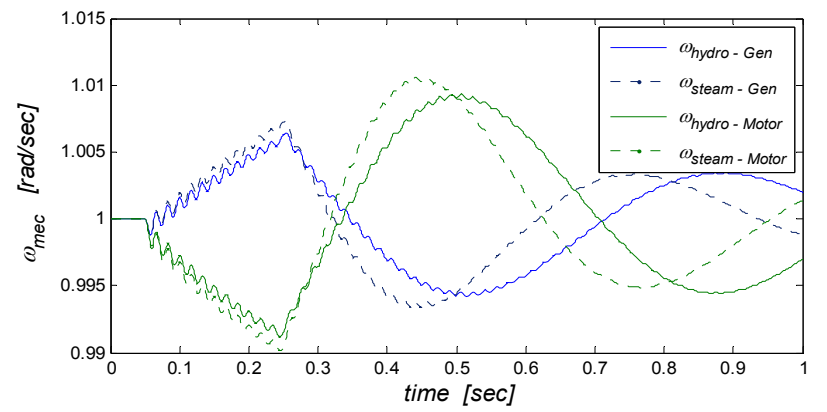

Fig. 5. Rotor speed $\left(\omega_{\mathrm{m}}\right)$ transient shape of both hydro turbine and steam turbine synchronous machines. (Sag type A, $h=20 \%, \Delta t=200 \mathrm{~ms}, \psi_{i}=15^{\circ}$ ). In both case, the machines are operating as a generator as a motor.

Due to the fact that synchronous machine may lose synchronism for the most severe voltage sags (large duration and depth), one important issue is to determinate the transient stability limit and the critical clearing time for each specific case. Consequently, in order to analyze the stability machine is necessary to consider various methods to permit to define these stability limits of the machine. This is treated below.

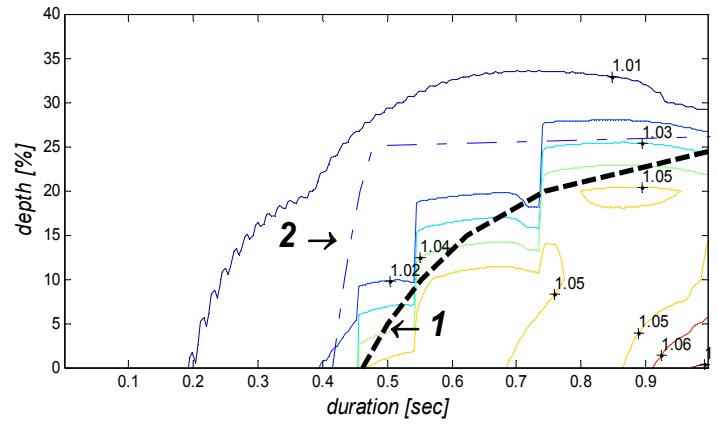

(a)

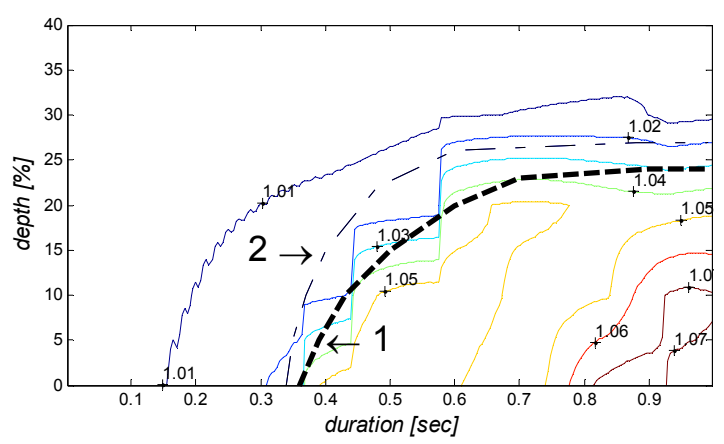

(b)

Fig. 6. Symmetrical voltage sag's durations and depth influence on the rotor speed $\left(\omega_{\mathrm{m}}\right)$ of a hydro turbine (a) and a steam turbine (b) SM. (Sag type A, $h=0 \%-100 \%, \Delta t=0-1$ second, $\psi_{i}=15^{\circ}$ )

Fig. 6(a) shows simulation results of several symmetrical sags applied on a hydro turbine synchronous generator. This figure is the result of recursive simulations with depth $h=0 \%$ to $100 \%$ and duration $\Delta t=0$ to 1 second. In this case, the initial point-on-wave is kept at $15^{\circ}$ for all simulations. Thus, this figure indicates the rotor speed peaks in absolute values and per unit (p.u.).

In addition, real and approximated stability machine limits have been represented. The thick dotted line (identified with number one) in Fig. 6(a) indicates the real stability machine limits (when the synchronous generator is unable to return to its steady state value), obtained by using the dynamic equations of the SM. Regarding to the thin dotted line (identified with number two) in the same figure, it indicates the approximated limits of the machine's stability, obtained by using the equalarea criterion described in [8], not only to short circuits, but also extended to voltage sags in order to determine the critical clearing time.

This method considers the approximated transient torqueangle curve, which along with the equal-area criterion is often used to predict the large excursion dynamic behaviour of a synchronous machine during a system fault (Fig. 7). Assume that the input torque $T_{i n}$ is constant and the machine is operating steadily, delivering power to the system with a rotor angle $\delta_{0}$ (point $O$ ). When the voltage sag occurs at the terminals, the power out (and the approximate torque) drops lineally proportional to sag's depth, and then the machine 
accelerates. The fault is cleared at $\delta_{1}$, and in this case the torque immediately becomes the value of the approximate transient torque (point D). In Fig. 7, the area $O A B C O$ is the energy stored in the rotor during the acceleration. After the clearing of the fault the rotor decelerates back to synchronous speed at $\delta_{2}$. The energy given up by the rotor during this time is represented by area $C D E F C$.

Therefore, in order to maintain synchronism in the machine after voltage sag, the follow mathematic expression must be accomplished.

$$
\int_{\delta_{0}}^{\delta_{1}}\left[\Gamma_{\text {load }}(\delta)-\Gamma_{\text {sag }}(\delta)\right] d \delta \leq \int_{\delta_{1}}^{\delta_{2}}\left[\Gamma_{\text {aprox }}(\delta)-\Gamma_{\text {load }}(\delta)\right] d \delta
$$

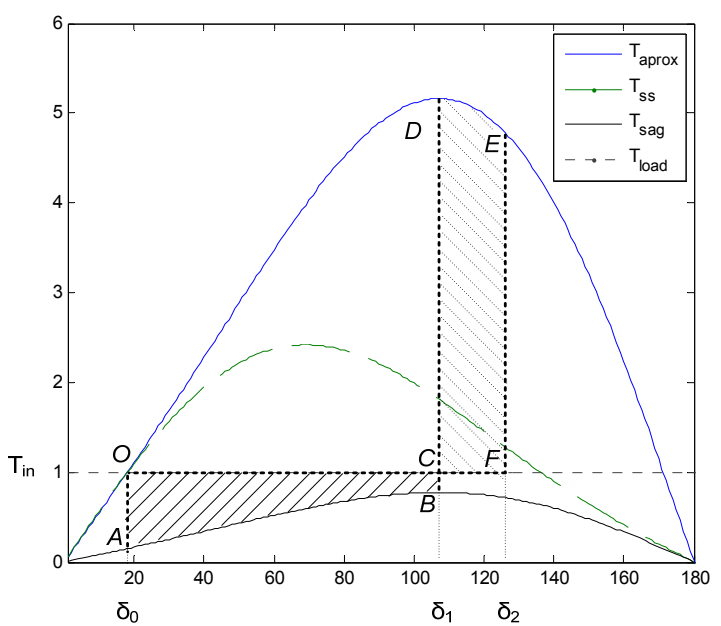

Fig. 7. Equal-area criterion extended to voltage sags: Torque vs. load angle curve (Symmetrical sags on hydro turbine synchronous generator)

Fig. 6(b) show the rotor speed peaks on the steam turbine synchronous generator, which has a similar behaviour with respect to the above one, but the synchronism is lost for shorter sag duration. The voltage sags characteristics in this case are the same ones. In both machines, all simulations were made considering symmetrical voltage sags because they are the cause of worst peaks.

Another method for determining the loss of synchronism in the machine is to take into account the load angle. The ability to keep the synchronism may be defined as the case when the load angle is below $180^{\circ}$ for all the time during and after the voltage sag [4].

This can be seen clearly in Fig. 8, where several symmetrical sags have been simulated on both hydro turbine and steam turbine SM. This figure shows the load angle peaks and has been obtained through recursive simulations with depth $h=0 \%$ to $100 \%$ and duration $\Delta t=0$ to 1 second and the initial pointon-wave is kept at $15^{\circ}$ for all simulations. In this figure the dotted line indicates the stability machine limits.

The SM behaviour when it is overexcited is different from the behaviour when it is underexcited (considering either motor or generator mode of operation).

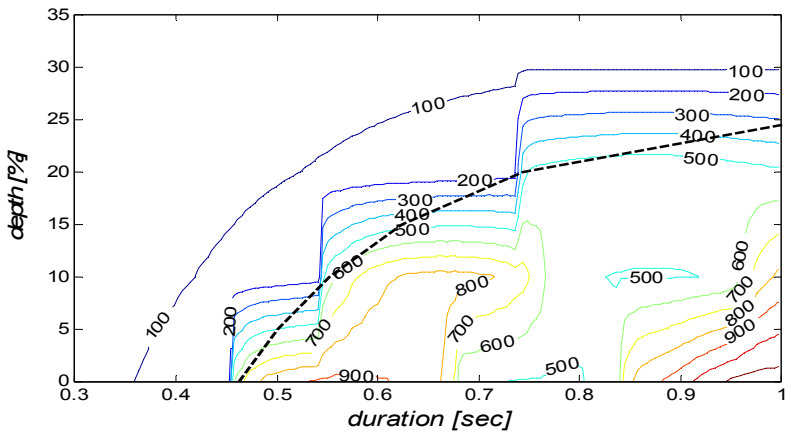

(a)

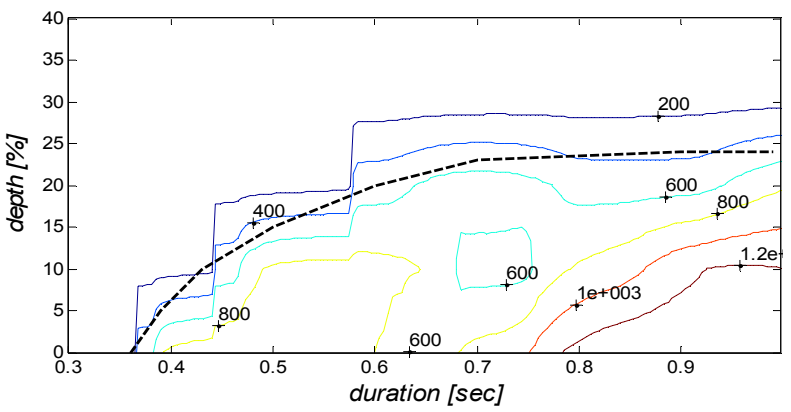

(b)

Fig. 8. Symmetrical voltage sag's durations and depth influence on the load angle $(\delta)$ of a hydro turbine (a) and a steam turbine (b) SM. (Sag type A, $h$ $=0 \%-100 \%, \Delta t=0-1$ second, $\psi_{i}=15^{\circ}$ )

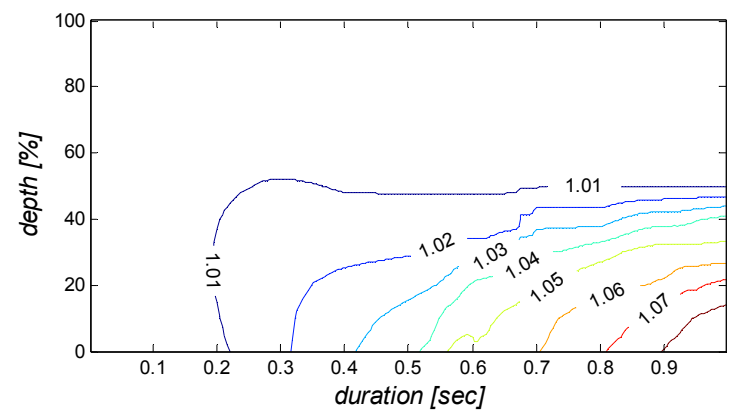

(a) Overexcited

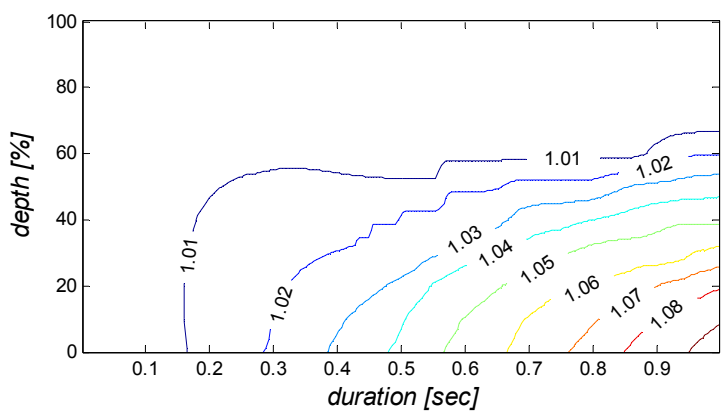

(b) Underexcited

Fig. 9. Symmetrical voltage sag's durations and depth influence on the rotor speed $\left(\omega_{\mathrm{N}}\right)$ of a $5 \mathrm{kVA}$ SM (Sag type A, $h=0 \%-100 \%, \Delta t=0-1$ second, $\psi_{i}=$ $\left.15^{\circ}\right)$ 
An overexcited SM is more stable than an underexcited one [9]. This situation can be confirmed from Fig. 9, where several symmetrical sags have been simulated by considering a $5 \mathrm{kVA}$ SM working as a generator. In all the simulations the following parameters have been considered: depth $h=0 \%$ to $100 \%$, duration $\Delta t=0$ to 1 second and the initial point-on-wave is set in $15^{\circ}$. As it is shown in Fig. 9(a), the rotor speed of the overexcited generator is more stable (with deeper voltage sag and when the sag duration is larger) than the same generator when it is underexcited (Fig. 9(b)). Using the load angle leads to the same conclusion.

\section{CONCLUSIONS}

Synchronous machine stability under voltage sags has been analyzed on three different three-phase SM's. Voltage sag effects on equipment depend on different elements such as sag characteristics (depth, duration, point-on-wave and type of sag), equipment and grid. The depth and duration influence on the torque peaks are linear and periodical, respectively, for all sag types.

The most relevant voltage sag effects on SM are current and torque peaks and possible loss of synchronism. The synchronous generator will be unable to return to its steady state value if the load angle is not below $180^{\circ}$ for all the time during and after the voltage sag. It should be noted that there have been no significant differences in the simulation of the $\mathrm{SM}$ in a motor or generator operation mode, but an overexcited $\mathrm{SM}$ is more stable than an underexcited one.

APPENDIX

RATEd DATA OF STEAM TURBINE SYNCHRONOUS GENERATOR

\begin{tabular}{|c|c|c|c|}
\hline$S_{N}:$ & 835MVA & $r_{S}:$ & $0.00243 \Omega$ \\
\hline$f_{N}:$ & $60 \mathrm{~Hz}$ & $r f:$ & $0.00075 \Omega$ \\
\hline$\omega_{N}:$ & $3600 \mathrm{r} / \mathrm{min}$ & $L_{0}:$ & $0.40796 \mathrm{mH}$ \\
\hline$U_{N}:$ & $26 \mathrm{kV}$ & $L_{s d}:$ & $3.86481 \mathrm{mH}$ \\
\hline$H:$ & $5.6 \mathrm{~s}$ & $L_{s q}:$ & $3.86481 \mathrm{mH}$ \\
\hline Poles: & 1 pole pair & $L_{f}:$ & $3.76056 \mathrm{mH}$ \\
\hline $\cos \varphi_{N}$ & 0.85 & $M_{d F}:$ & $3.45684 \mathrm{mH}$ \\
\hline$J:$ & $65.8 \times 10^{3} \mathrm{Js}^{2}$ & $M_{q}:$ & $3.45684 \mathrm{mH}$ \\
\hline \multicolumn{4}{|c|}{ RATED DATA OF HYDRO TURBINE SYNCHRONOUS GENERATOR } \\
\hline$S_{N}:$ & $325 \mathrm{MVA}$ & $r_{s}:$ & $0.00234 \Omega$ \\
\hline$f_{N}:$ & $60 \mathrm{~Hz}$ & $r_{f}:$ & $0.00050 \Omega$ \\
\hline$\omega_{N}:$ & $112.5 \mathrm{r} / \mathrm{min}$ & $L_{0}:$ & $0.39205 \mathrm{mH}$ \\
\hline$U_{N}:$ & $20 \mathrm{kV}$ & $L_{s d}:$ & $2,77645 \mathrm{mH}$ \\
\hline$H$ & $7.5 \mathrm{~s}$ & $L_{s q}:$ & $1.56794 \mathrm{mH}$ \\
\hline Poles: & 32 pole pairs & $L_{f}:$ & $3.05365 \mathrm{mH}$ \\
\hline $\cos \varphi_{N}$ & 0.85 & $M_{d F}:$ & $2.3844 \mathrm{mH}$ \\
\hline$J:$ & $35.1 \times 10^{6} \mathrm{JS}^{2}$ & $M_{q}:$ & $1.1759 \mathrm{mH}$ \\
\hline \multicolumn{4}{|c|}{ RATED DATA OF 5KVA SYNCHRONOUS MACHINE } \\
\hline$S_{N}:$ & $5 \mathrm{kVA}$ & $r_{s}:$ & $4.97 \Omega$ \\
\hline$f_{N}:$ & $60 \mathrm{~Hz}$ & $r f:$ & $0.35 \Omega$ \\
\hline$\omega_{N}:$ & $3600 \mathrm{r} / \mathrm{min}$ & $L_{0}:$ & $4.97 \mathrm{mH}$ \\
\hline$U_{N}:$ & $437 \mathrm{~V}$ & $L_{s d}:$ & $111.45 \mathrm{mH}$ \\
\hline$H:$ & $3.55 \mathrm{~s}$ & $L_{s q}:$ & $65.39 \mathrm{mH}$ \\
\hline Poles: & 1 pole pair & $L_{f}:$ & $111.80 \mathrm{mH}$ \\
\hline $\cos \varphi_{N}:$ & $0.85(\mathrm{i})$ & $M_{d F}:$ & $106.48 \mathrm{mH}$ \\
\hline$J:$ & $0.2498 \mathrm{Kg} \mathrm{m}^{2}$ & $M_{q}:$ & $60.41 \mathrm{mH}$ \\
\hline
\end{tabular}

\section{ACKNOWLEDGMENT}

This research work was supported by the project ENE200806588-C04-03/ALT from the Spanish Ministry of Education and Science.

\section{REFERENCES}

[1] P. Kundur, Power System and Stability Control, Mc. Graw Hill, New York, 1994.

[2] M. H.J. Bollen, Understanding Power Quality Problems, IEEE Press, New York, 1999

[3] L. Guasch, Effects of Voltage Sags on Induction Machine and Transformers, University Polytechnic of Catalonia. pp. 56-62, Jan. 2006.

[4] F. Carlsson, J. Engstrom and C. Sadarangani: Before and during voltage sags, IEEE Industry Application Magazine, Vol 11 no 2, pp. 39- 46.

[5] D. Aguilar, A. Luna, A. Rolan, G. Vazquez, G. Acevedo, Modelling and Simulation of Synchronous Machine and its behaviour against Voltage Sags, IEEE International Symposium on Industrial Electronics, Jun 2009

[6] IEEE Recommended Practice for Monitoring Electric Power Quality, IEEE Standard 1159- 2009, June 26, 2009.

[7] L. Guasch, F. Córcoles and J. Pedra, Effects of Symmetrical and Unsymmetrical Voltage Sags on Induction Machines, IEEE, Trans. Power Delivery, vol. 19, No. 2, pp. 774-782. April 2004.

[8] P. C. Krause, Analysis of Electric Machinery, McGraw-Hill, New York, 1986.

[9] J. C. Das, Effects of Momentary Voltage Dips on the Operation of Induction and Synchronous Motors, IEEE, Trans. Industry Application, Vol 26, No. 4, July/August 1990. 